\title{
Spermiotaxonomy of the tribe Rhodniini (Hemiptera, Triatominae)
}

\author{
A. Ravazi ${ }^{1}$, J. Oliveira ${ }^{2}$, J.A. Rosa ${ }^{2}$, M.T.V. Azeredo-Oliveira ${ }^{1}$ and K.C.C. Alevi ${ }^{1}$ \\ ${ }^{1}$ Laboratório de Biologia Celular, Departamento de Biologia, \\ Instituto de Biociências, Letras e Ciências Exatas, \\ Universidade Estadual Paulista "Júlio de Mesquita Filho", \\ São José do Rio Preto, SP, Brasil \\ 'Laboratório de Parasitologia, Departamento de Ciências Biológicas, \\ Faculdade de Ciências Farmacêuticas, \\ Universidade Estadual Paulista "Júlio de Mesquita Filho", Araraquara, SP, Brasil \\ Corresponding author: K.C.C. Alevi \\ E-mail: kaiochaboli@hotmail.com \\ Genet. Mol. Res. 15 (1): gmr.15017366 \\ Received August 5, 2015 \\ Accepted November 13, 2015 \\ Published March 24, 2016 \\ DOI http://dx.doi.org/10.4238/gmr.15017366
}

\begin{abstract}
The tribe Rhodniini is a monophyletic group composed of 22 species, with 19 in the Rhodnius genus and three in the Psammolestes genus. These insects are morphologically very similar (cryptic species), and new tools are important for investigating the taxonomy of these vectors. Spermiotaxonomy is an important tool in differentiating between related species, and this study analyzed the spermatids of Rhodniini species to elucidate their spermiotaxonomy. All of the Rhodniini species contained two heteropyknotic filaments in the extremities of their cells. Although spermiotaxonomy has been an important tool in differentiating between species of the Triatoma genus, all of the species in the Rhodnius genus exhibited the same characteristics in their male gametes. However, spermatid analysis made it possible to confirm the monophyly of the Rhodniini tribe, because Psammolestes tertius had the same pattern as that described for Rhodnius. The results of this study demonstrate that spermiotaxonomy, in addition to being an important tool for differentiating between related species of Triatoma, can be used as an optimization tool in phylogenetic analyses.
\end{abstract}

Key words: Rhodnius; Psammolestes; Spermiogenesis; Cytotaxonomy 


\section{INTRODUCTION}

The triatomines are insects that belong to the Hemiptera order, Heteroptera suborder, Reduviidae family, and Triatominae subfamily (Lent and Wygodzinsky, 1979). The Triatominae subfamily is composed of 150 species, grouped in 18 genera and six tribes (Alevi et al., 2015). All of the species of the subfamily are bloodsucking and potential vectors of the Trypanosoma cruzi protozoan, which is an etiological agent of Chagas disease (Noireau et al., 2009).

The tribe Rhodniini is a monophyletic group (Monteiro et al., 2000) composed of 22 species, with 19 in the Rhodnius genus and three in the Psammolestes genus (Rosa et al., 2012; Alevi et al., 2012; Abad-Franch et al., 2013). These insects are morphologically very similar (cryptic species) (Monteiro et al., 2000), and new tools are important for investigating the taxonomy of these vectors.

Recently, spermiotaxonomy was used in the Triatoma genus to differentiate between related species (Alevi et al., 2013a, 2014). Cytogenetic analysis of male gametes of Triatoma melanocephala and T. vitticeps, which are considered sister species (Alevi et al., 2013b; Gardim et al., 2014), allowed the differentiation of these species (Alevi et al., 2014). In addition, the same analysis also made it possible to differentiate T. lenti from T. sherlocki (Alevi et al., 2013a). Therefore, this study aimed to analyze spermatids of species of the Rhodniini tribe to elucidate the spermiotaxonomy of these vectors.

\section{MATERIAL AND METHODS}

Three adult males of each species (Table 1) were cytogenetically analyzed. The insects were donated by "Insetário de Triatominae" of the Biological Sciences Department of the Faculty of Pharmaceutical Sciences, State University of São Paulo, Campus Araraquara, São Paulo, Brazil. Microscope slides with the biological material (seminiferous tubules) were prepared by the crushing technique and stained with lacto-acetic orcein (De Vaio et al., 1985) with modifications by Alevi et al. (2012). The slides were analyzed using a Jenavallight microscope (Zeiss) coupled to a digital camera and an AxioVision LE 4.8 image analyzer (Zeiss). The images were magnified by 1000X.

\section{RESULTS}

All of the species of the Rhodniini tribe exhibited the same spermatid characteristics, i.e., the presence of two heteropyknotic filaments in the extremities of their cells (Figure 1 and Table 1).

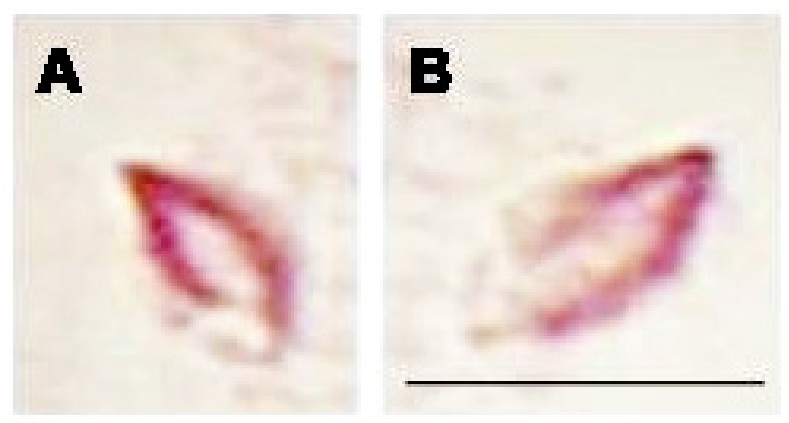

Figure 1. Early spermatids of Psammolestes tertius (A) and Rhodnius montenegrensis (B). All of the species analyzed had two heteropyknotic filaments in their haploid cells. Bar: $10 \mu \mathrm{m}$. 
Table 1. Heteropyknotic patterns in spermatids of species of the tribe Rhodniini.

\begin{tabular}{l|l|l}
\hline Species & Heteropyknotic pattern in spermatids & Reference \\
\hline Rhodnius colombiensis & Two heteropyknotic filaments & This study \\
\hline Rhodnius domesticus & Two heteropyknotic filaments & Morielle and Azeredo-Oliveira (2004) \\
\hline Rhodnius montenegrensis & Two heteropyknotic filaments & This study \\
\hline Rhodnius nasutus & Two heteropyknotic filaments & This study \\
\hline Rhodnius neglectus & Two heteropyknotic filaments & This study \\
\hline Rhodnius neivai & Two heteropyknotic filaments & This study \\
\hline Rhodnius pictipes & Two heteropyknotic filaments & This study \\
\hline Rhodnius prolixus & Two heteropyknotic filaments & This study \\
\hline Rhodnius robustus & Two heteropyknotic filaments & This study \\
\hline Psammolestes tertius & Two heteropyknotic filaments & This study \\
\hline
\end{tabular}

\section{DISCUSSION}

Abad-Franch et al. (2013) suggested that there may be many errors related to the taxonomy of the genus Rhodnius, mainly because of cryptic species. The authors propose that $R$. milesi is probably an $R$. neglectus variant from south-eastern Amazonia, $R$. zeledoni closely resembles $R$. domesticus, and $R$. montenegrensis probably represents one of the $R$. robustus lineages (Monteiro et al., 2000).

Although spermiotaxonomy has been an important tool in differentiating between triatomines of the Triatoma genus (Alevi et al., 2013a, 2014), all of the species in the Rhodnius genus exhibited the same male gamete characteristics. Therefore, the taxonomic issues raised by Abad-Franch et al. (2013) could not be assessed using this tool.

However, spermatid analysis made it possible to confirm the monophyly of the Rhodniini tribe, because $P$. tertius exhibited the same pattern as described for Rhodnius. This phylogenetic relationship was proposed by Lent and Wygodzinsky (1979) based on morphological characteristics, and by Monteiro et al. (2000) based on molecular analyses. This parameter was recently used to evaluate relationships between species of the Brasiliensis subcomplex, and it was possible to exclude T. melanocephala, T. vitticeps, and T. tibiamaculata, as well as suggest that $T$. lenti is the sixth subcomplex member (Alevi et al., 2014). The results of this study demonstrate that spermiotaxonomy, in addition to being an important tool for differentiating between related species of Triatoma, can be used as an optimization tool in phylogenetic analyses.

\section{Conflicts of interest}

The authors declare no conflict of interest.

\section{ACKNOWLEDGMENTS}

Research supported by Fundação deAmparo à Pesquisa do Estado de São Paulo (FAPESP; Processes \#2013/19764-0 and \#2014/04521-8) and Conselho Nacional de Desenvolvimento Científico e Tecnológico (CNPq).

\section{REFERENCES}

\footnotetext{
Abad-Franch F, Pavan MG, Jaramillo-O N, Palomeque FS, et al. (2013). Rhodnius barretti, a new species of Triatominae (Hemiptera: Reduviidae) from western Amazonia. Mem. Inst. Oswaldo Cruz 108 (Suppl 1): 92-99.http://dx.doi. org/10.1590/0074-0276130434
} 
Alevi KCC, Mendonça PP, Pereira NP, Rosa JA, et al. (2012). Karyotype of Triatoma melanocephala Neiva and Pinto (1923). Does this species fit in the Brasiliensis subcomplex? Infect. Genet. Evol. 12: 1652-1653.http://dx.doi.org/10.1016/j. meegid.2012.06.011

Alevi KC, Mendonça PP, Pereira NP, Fernandes AL, et al. (2013a). Analysis of spermiogenesis like a tool in the study of the triatomines of the Brasiliensis subcomplex. C. R. Biol. 336: 46-50.http://dx.doi.org/10.1016/j.crvi.2013.01.005

Alevi KC, Mendonça PP, Pereira NP, Rosa JA, et al. (2013b). Spermatogenesis in Triatoma melanocephala (Hemiptera: Triatominae). Genet. Mol. Res. 12: 4944-4947.http://dx.doi.org/10.4238/2013.October.24.5

Alevi KCC, Rosa JA and Azeredo-Oliveira MT (2014). Cytotaxonomy of the Brasiliensis subcomplex and the Triatoma brasiliensis complex (Hemiptera: Reduviidae: Triatominae). Zootaxa 3838: 583-589.http://dx.doi.org/10.11646/ zootaxa.3838.5.7

Alevi KCC, Moreira FFF, Jurberg J and Azeredo-Oliveira MTV (2015). Description of diploid chromosome set of Triatoma pintodiasi (Hemiptera, Triatominae). Genet. Mol. Res., in press. http://dx.doi.org/10.4238/2015.February.6.14

De Vaio ES, Grucci B, Castagnino AM, Franca ME, et al. (1985). Meiotic differences between three triatomine species (Hemiptera: Reduviidae). Genetica 67: 185-191. http://dx.doi.org/10.1007/BF02424489

Gardim S, Almeida CE, Takiya DM, Oliveira J, et al. (2014). Multiple mitochondrial genes of some sylvatic Brazilian Triatoma: non-monophyly of the $T$. brasiliensis subcomplex and the need for a generic revision in the Triatomini. Infect. Genet. Evol. 23: 74-79.http://dx.doi.org/10.1016/j.meegid.2014.01.024

Lent $\mathrm{H}$ and Wygodzinsky P (1979). Revision of the Triatominae (Hemiptera: Reduviidae) and their significance as vector of Chagas's disease. Bull. Am. Mus. Nat. Hist. 163: 123-520.

Monteiro FA, Wesson DM, Dotson EM, Schofield CJ, et al. (2000). Phylogeny and molecular taxonomy of the Rhodniini derived from mitochondrial and nuclear DNA sequences. Am. J. Trop. Med. Hyg. 62: 460-465.

Morielle A and Azeredo-Oliveira MTV (2004). Description of the nucleolar activity and karyotype in germinative cell lines of Rhodnius domesticus (Triatominae, Heteroptera). Caryologia 57: 31-37. http://dx.doi.org/10.1080/00087114.2004.10589369

Noireau F, Diosque P and Jansen AM (2009). Trypanosoma cruzi: adaptation to its vectors and its hosts. Vet. Res. 40: 26.http:// dx.doi.org/10.1051/vetres/2009009

Rosa JA, Rocha CS, Gardim S and Pinto MC (2012). Description of Rhodnius montenegrensis n. sp. (Hemiptera: Reduviidae: Triatominae) from the state of Rondônia Brazil. Zootaxa 3478: 62-76. 